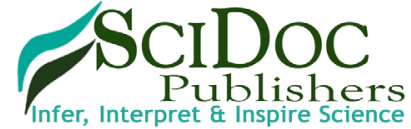

International Journal of Food Science, Nutrition and Dietetics (IJFS)

ISSN:2326-3350

\title{
Adequacy of Medical and Surgical Residents' Nutritional Education
}

Research Article

Ghanem $\mathrm{J}^{1}$, Wehbe $\mathrm{T}^{2 *}$, Abou Jaode $\mathrm{E}^{3}$

${ }^{1}$ The Holy Spirit University of Kaslik, Jounieh, Lebanon.

${ }^{2}$ The Lebanese Canadian and The Notre Dame University Hospital, Department of Hematology, Jounieh, Lebanon.

${ }^{3}$ The Middle East Institute of Health Hospital, Department of Endocrinology, Bsalim, Lebanon.

Abstract

Background and Objectives: Over the past years, nutritional and life style modifications have become an important adjunct to medical therapy especially with the widespread obesity epidemic. Furthermore, diseases related to obesity such as diabetes, heart disease, stroke, hypertension, hyperlipidemia and cancers are the leading causes of death worldwide. The doctors, considered by their patients, as the reference for nutritional advice, may not have received the necessary education to assume this important role. Several studies, from the U.S., Canada, Taiwan, the U.K and Iran, among others, showed poor knowledge about nutrition among physicians in training. The objective of this study is to test the knowledge of medical and surgical residents from different medical schools in Lebanon to perform dietary counseling.

Material and Methods: A cross-sectional study was conducted in 2015 among medical and surgical residents randomly selected from all seven medical schools in Lebanon. A standardized, published English language questionnaire was tested in a pilot assessment then adopted; it covered personal status, self-esteem, nutritional practice and nutritional knowledge. The survey was conducted in writing and included 20 standard nutrition knowledge questions.

Results: 398 residents from all 7 medical schools were enrolled. All 3 years of residency were represented. 65\% were Internal Medicine residents and 35\% surgical residents. $72.1 \%$ reported receiving no nutritional education during their training. Although $89.33 \%$ of the residents reported giving nutritional advice regularly, and $77 \%$ reported a high confidence about their knowledge, the average score on the test was 9.73 over 20 . A high number of medical residents reported encouraging their patients to consult a Registered Dietitian. Most scores did not exceed the average and the difference among the medical schools was not significant.

Conclusion: This study underscores the great need to establish nutritional education as a core discipline in the medical education in Lebanon given the central role it plays in today's clinical practice. Our results are alarming and should be taken into consideration to improve medical education and clinical practice. Future interventional studies would be of great value in assessing and setting reasonable goals for nutritional education targeting everyone on the medical team.

Keywords: Doctor's Education; Dietitians; Nutritional Knowledge; Nutrition Practice.

\section{Introduction}

According to the American Dietetic Association (ADA), Medical Nutritional Therapy (MNT), should be an initial and integral component of medical treatments for several conditions. The ADA encourages active collaboration among registered dieticians and other members of the health care team based on elaborate data.

Most patients consider their doctors as their reference on medical information including their nutrition. Nutrition is therefore an important part of every medical doctor's education and an essential part of the recommendations given by doctors to their patients when elaborating treatment plans [1]. However, training in nutrition during medical school years remains one of the major deficiencies of medical education [2-5].

The "process of support in setting priorities and goals, and creating individualized action plans that encourage accountability for managed care" as defined by the ADA remains far from reality [6]. Beyond fighting obesity as the disease of the century, the knowledge about food and nutrition has several medical applications

\author{
*Corresponding Author: \\ Wehbe Tarek, M.D, \\ Department of Hematology, The Lebanese Canadian and Notre Dame University Hospitals, Jounieh, Lebanon. \\ Tel: 03-734767 \\ E-mail: twwehbe4@gmail.com \\ Received: January 04, 2018 \\ Accepted: February 22, 2018 \\ Published: February 23, 2018 \\ Citation: Ghanem J, Wehbe T, Abou Jaode E. Adequacy of Medical and Surgical Residents' Nutritional Education. Int J Food Sci Nutr Diet. 2018;7(2):377-382. \\ doi: http://dx.doi.org/10.19070/2326-3350-1800067
}

Copyright: Wehbe $\mathbf{T}^{\mathfrak{O}}$ 2018. This is an open-access article distributed under the terms of the Creative Commons Attribution License, which permits unrestricted use, distribution and reproduction in any medium, provided the original author and source are credited. 
such as the interference of certain foods with drug efficacy [7]. One example is the interaction of Grapefruit with the metabolism of several drugs which can cause serious, sometimes fatal, adverse reactions. Another example is the excess intake of vitamin B6, a water-soluble vitamin, which can cause toxic sensory neuropathies [8]. In addition, the use of certain vitamins or minerals may decrease the effectiveness of certain drugs (for example, vitamin $\mathrm{C}$ and warfarin) [9].

Diabetes and obesity are considered major health issues of epidemic proportions all over the world. These conditions are greatly related to nutritional choices and behaviors. About 1.6 million new cases of diabetes are diagnosed each year worldwide. The incidence of diabetes in the general population of the United States is more than $10 \%$ for those aged 20 years or older and more than $23 \%$ for those aged 60 years or older [10]. The ADA strongly recommends MNT by a registered dietician as part of diabetes management and suggests that it has the greatest potential to impact diabetes patients once diagnosed [11]. Several studies reported HbA1C improvements of 0.9 to $1.9 \%$ for individuals receiving MNT in newly diagnosed type 1 diabetes, $2 \%$ in newly diagnosed type 2 diabetes (T2D), and 1\% in type 2 diabetes with a long duration averaging 4 years [12-14].

MTN was also shown to delay the onset of type 1 and T2D. Lifestyle modifications, including dietary changes have been proved in 16 studies to impact the outcomes in T2D. The ADA concluded that MNT is more effective than pharmacotherapy in reducing the incidence of T2D $[15,16]$. MNT may also reduce the risk of peri-natal complications, and improve the likelihood of normal growth of the fetus and placenta [17].

Another condition closely related to nutrition is Heart failure which affects approximately 5 million Americans and contributes to 300,000 deaths each year. Sodium restriction and controlled fluid intake are important elements of non-pharmacological therapy [18]. In the case of acute myocardial infarction, eight of the 9 main risk factors are influenced by nutrition [19]. In addition, the anticoagulant Warfarin, often prescribed in heart failure, interacts with vitamin $K$, and patients are advised to maintain a consistent vitamin $\mathrm{K}$ intake [20].

The dietary approaches to stop the progression of hypertension (DASH DIET), includes dietary modifications in micro and macronutrients to lower systolic blood pressure (SBP) by 8 to $14 \mathrm{~mm}$ $\mathrm{Hg}$ while 30 minutes of physical activity on most days could lower the SBP by 4 to $9 \mathrm{mmHg}$. Maintaining a 2,300 $\mathrm{mg}$ of sodium intake could reduce SBP by 2 to $8 \mathrm{mmHg}$, while restricting daily intake to $1,600 \mathrm{mg}$ of sodium can give similar results to single drug therapy in some individuals. Similar studies have shown the beneficial effects of low-fat vegetables, fruits and dairy products $[21,22]$.

Every dollar spent on MNT may save about $\$ 3.58$ or more in treatment. The combination of MNT and drugs for the treatment of more severe forms of lipid disorders allows to lower pharmacological doses and side effects related to medical treatments alone $[23,24]$. Osteoporosis therapy starts with adjusting the intake of calcium and vitamin D $[25,26]$. Implementing a gluten-free diet for patients with celiac disease, preventing kidney disease progression, avoiding hemolysis in G6 PD deficiency, avoiding gout attacks, preventing malnutrition, Bulimia, Anorexia, Cancers, among others are all illustrations of how nutrition has a major role to be played in human conditions and diseases [27-30].

However, study after study have found that physicians are reluctant to provide nutritional information to patients because of low confidence resulting from the poor or lack of education and knowledge in this area according to the National Health Promotion and Disease Prevention Objectives [31].

The purpose of this study is to uncover, once more, the deficits in dietary knowledge among physicians and the missed opportunities to help patients by adjusting their dietary intake. Medical Schools and educators should be alerted to this major issue. Future studies should look into streamlining the results of such education on patient's health and different outcome measures in interventional long term follow up studies.

\section{Materials and Methods}

This is a cross-sectional study conducted over a period of four months, between August and November 2015. An informed consent form and the study questionnaire were approved by the Ethics Committee in the Department of Health, Human Nutrition and Dietetics of the Faculty of Agricultural and Food Sciences of the Holy Spirit University of Kaslik, Lebanon.

The population of this study was restricted to residents of all faculties of medicine and surgery at universities in Lebanon. There are seven registered medical universities: The American University of Beirut (AUB), Beirut Arab University (BAU), the Lebanese American University (LAU), the Lebanese University (UL), the Holy Spirit University of Kaslik (USEK), Saint Joseph University of Beirut (USJ), and University of Balamand (UOB).

It is estimated that the entire population of residents is made up of approximately 1260 medical residents ( 7 universities x 3 years of study x 60 students per year). The inclusion criteria were age between 20 and 40 years; residents registered in one of the first 3 years of a medical or surgical specialty. The exclusion criteria were the following: Students from foreign universities, or not satisfying the inclusion criteria.

After having been tested and verified, a general questionnaire in English was adopted (Supplement 1). The questionnaire covered personal status, self-esteem, nutritional practice, and a general nutrition test with 20 standardized questions. The part on the personal evaluation and nutrition practice were extracted from the questionnaire validated in "Nutrition in Patient Care Survey (NIPS)" developed by Mihalynuk (2003). The test of knowledge in nutrition was adapted from the test prepared by Vetter (2008) $[32,33]$.

\section{Statistical Analysis}

The data was collected on the SPSS (Statistical Package for Social Sciences) version 2.0 and on Microsoft Excel. An exhaustive descriptive exploration of all the variables in the study was used to obtain a detailed description of the sample: the average age, distributions of participants by gender, by university and by year of study. In order to identify a statistically significant difference, an 
ANOVA variance analysis was used with a Duncan post hoc test grouping. Similarly, a parametric correlation analysis (Pearson's R) and a non-parametric one (Spearman's Rho) were performed to study the relationships between the different variables analyzed. In all the statistical tests performed, a significance level of 0.05 was used.

\section{Results}

This study involved a total of 398 residents, including 222 men and 176 women. The selection of the sample was random with respect to gender. The average age was $27.26 \pm 2.2$ years. The age range was 23 to 34 years (Figure 1).

The Universities were represented by numbers one through seven for the analysis. The differences in the number of medical residents recruited was related to several criteria including the permission given by universities and hospitals, plus the availability and cooperation of physicians.

The sample distribution included all 3 years of residency as follows 168 first year residents, 115 second year and 115 third year residents (Figure 2). The largest number was 50 physicians in University number 5 in their first year of residency and the lowest number was 5 physicians in University 4 in his third year of residency.

The sample was subdivided into: internal medicine and surgery. 111 doctors reported receiving training in nutrition during their medical school years $(27.9 \%)$ while 287 doctors reported receiving none (72.1\%) (Figure 3).

Most (92\%) of the medical residents reported encouraging their patients to visit a registered dietitian for MNT. In addition, 87.2\% reported using MNT with advanced pharmacological treatments where possible and necessary. Although those percentages indicate a high awareness among the residents of the importance of nutritional treatments, the scores of the residents on the nutritional tests were disappointedly very low averaging $9.7 / 20$ or, in other words, only 48.5 percent of the answers were correct on the average. The mean score of the surgical residents was lower than that of the internal medicine residents.

The results also reflected a highly significant difference in the nutrition knowledge test scores among the different universities ( $p$ $<0.001)$ although all of the residents belonging to all the universities did poorly on the test. The lowest self-assessment/esteem results belonged to the university which received the lowest scores on the test (university 5).

Universities 4 and 5 scored the lowest average (8.3/20). Nevertheless, the highest averages were still poor reaching 10-10.7 over 20 (universities 1, 2, 3 and 6) (Figure 4).

Among the seven medical schools in Lebanon, three adopt the French international education system, three adopt the American system and one follows the British system.

Comparing the French (9.66/20) and American (9.53/20) systems, we found no significant difference in the total scores on the nutrition knowledge test $(p=0.694)$. Similarly, we found no significant difference $(p=0.150)$ in scores or self-esteem between the group of physicians who reported receiving nutrition training and those who did not. There was a highly significant difference in self-esteem among the different universities but that did not correlate with the actual knowledge $(p=0.76)$.

\section{Discussion}

This study confirms the fact that nutritional knowledge among medical and surgical residents is, at best, sub-optimal. These findings are probably due to several factors including the structure of the medical curricula, the attitude of the residents in regards to nutritional knowledge, and the way nutritional advice is being incorporated into medical therapy. The surgical residents had the lowest scores reflecting a complete disinterest in the subject of medical nutrition and a faulty assumption that nutrition is not relevant enough for the act of surgery although several studies stress the importance of nutrition in reducing morbidity and postoperative mortality.

Nutrition education is not a part of the curriculum as most resi-

Figure 1. Distribution of the resident's age.

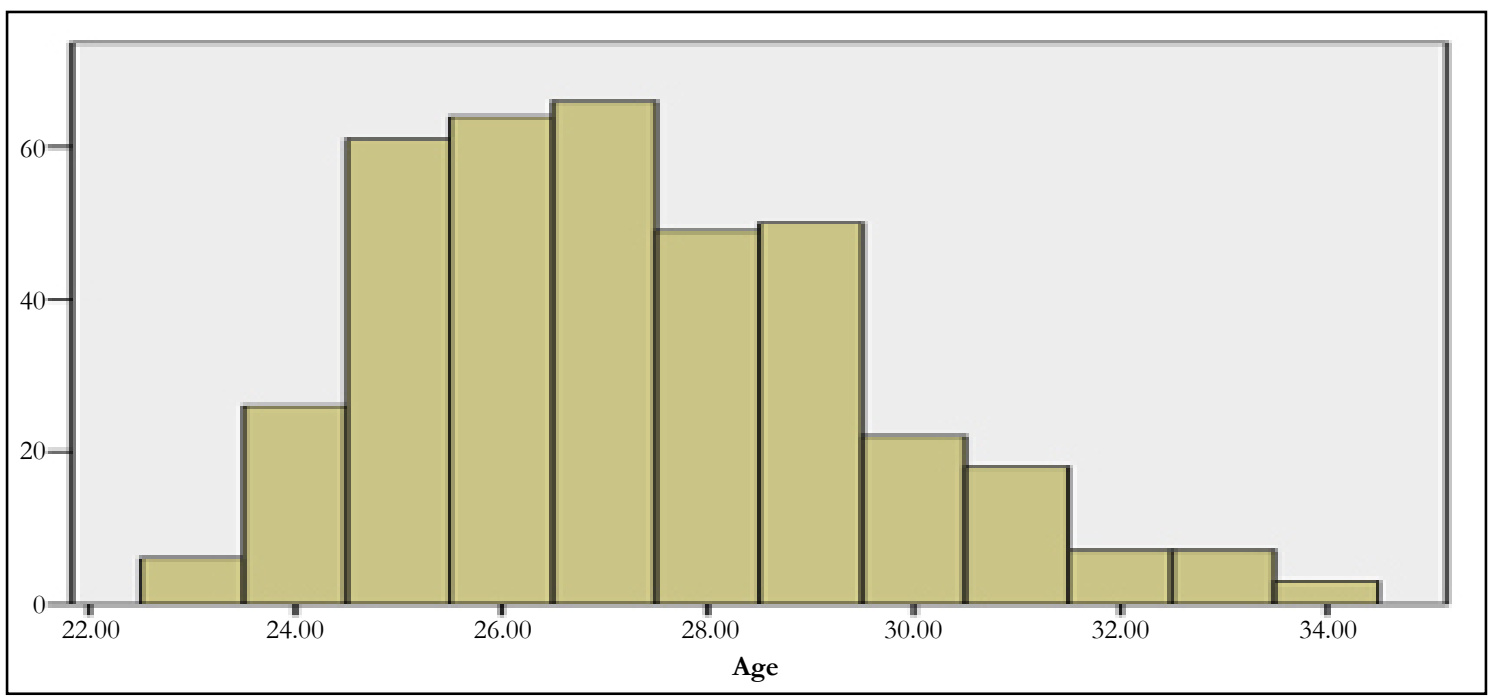


Figure 2. Distribution of the residents according to the year and university.

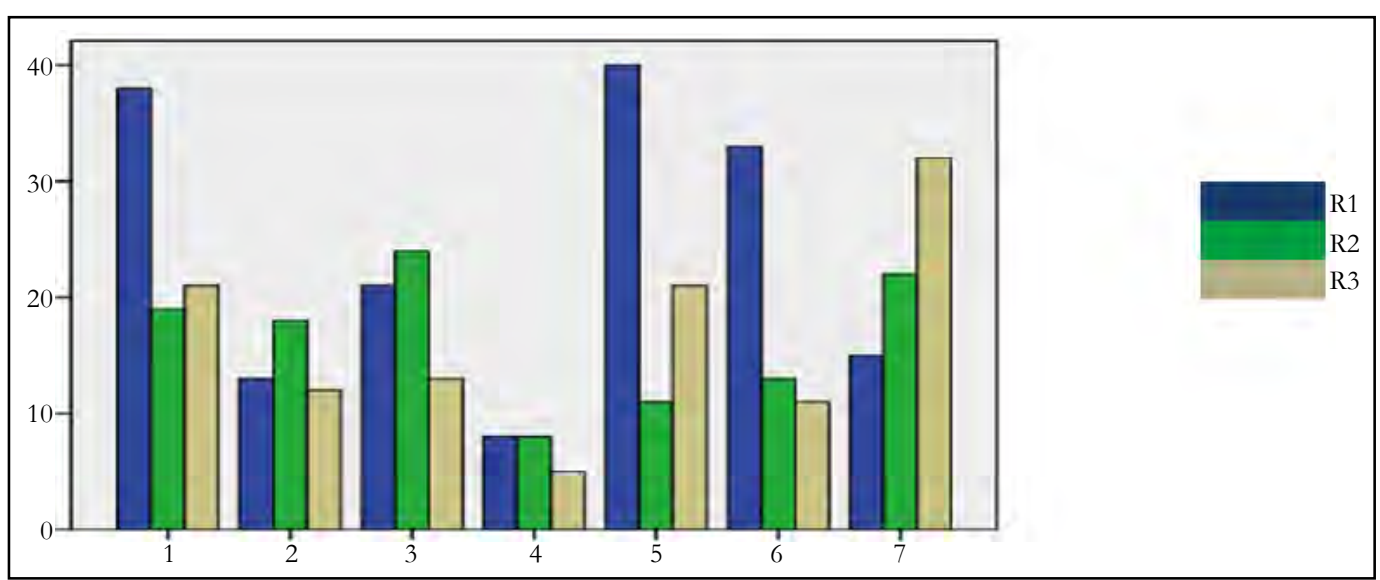

Figure 3. Distribution of residents who reported receiving any nutrition education (YES) and those reporting no such education was received (NO).

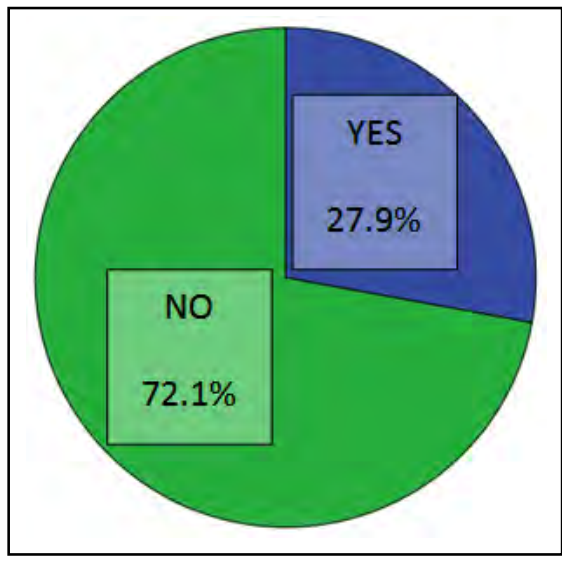

Figure 4. Difference of the scores on the nutrition knowledge among the universities.

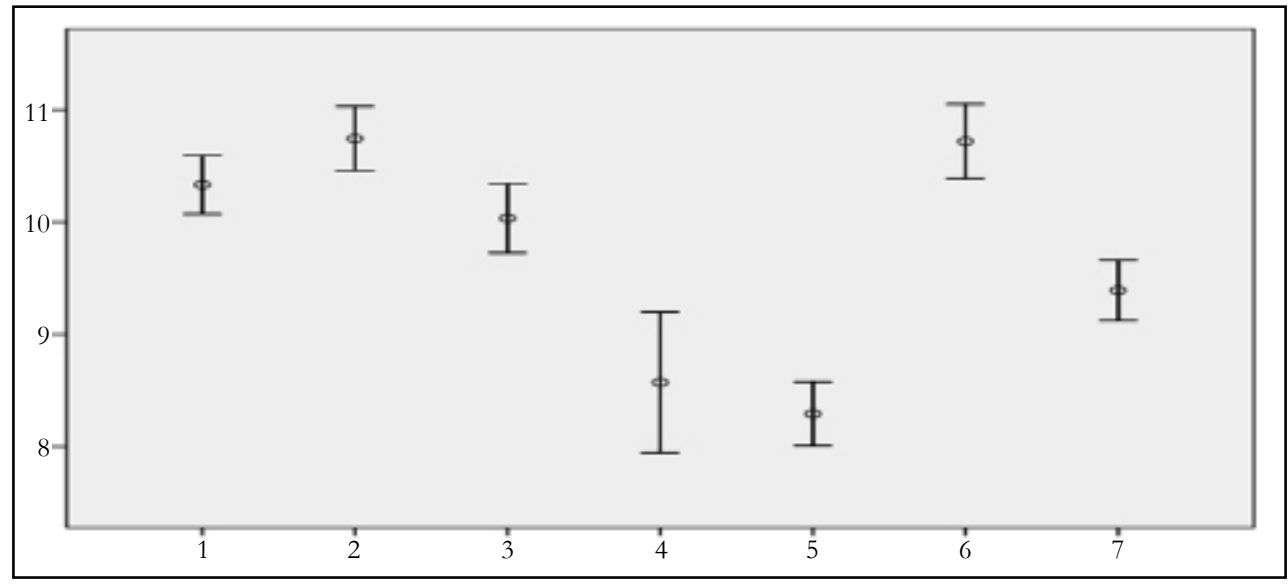

dents reported. The residents reported that with the advancement of the years of study, the percentage of the nutritional practice increases. This probably reflects the progressive awareness of the importance of nutrition to medical practice but not to the point where the residents sought advanced nutritional education.

Interestingly, over the years of residency, self-esteem increases (R1:74, R2:78, R3:79) but the total nutritional knowledge decreases (R1: 9.95, R2: 9.74, and R3: 9.5). This is due to an ego that rises with the practice of medicine but a nutrition knowledge that erodes with time.

Of note is the fact that self-esteem did not correlate significantly with the nutritional knowledge score among different universities, reflecting a gap between what residents think of themselves and what they actually know, this may reflect a general trend among practicing physicians and those in the academic field.

These findings may also be due to the fact that residents and doctors develop the assumption that patients needing advanced nutritional counseling can be referred to a nutrition specialist.

Surgeons were especially disinterested in nutrition knowledge over the years of training reflecting the trend of leaving this part of practice to others, perhaps nutrition specialists [34]. It would be interesting to study if the patterns of referrals reflected this 
belief.

Our results are similar to other studies around the world where the scores obtained reflected on the average, about $48.5 \%$ scores on the nutritional knowledge quiz [2, 4, 5, 35].

Self-esteem is high, unlike actual knowledge scores in nutrition. In percentage terms, $77 \%$ of participants were confident that they were able to assess the nutritional status of their patients and discuss general nutritional issues, unlike the findings of Vetter et al., in a study of the U.S. residents reflecting a low self assessment when it comes to nutritional knowledge [33]. This study, similar to others, also shows the deterioration of the nutritional information over the years of study in medicine reflecting an absent or deficient continuing education [36].

\section{Conclusion}

In this study, we used a questionnaire to examine the medical and surgical resident's nutritional knowledge, attitudes and self-assessment. Despite a significant difference among universities, there is a widespread sub-optimal nutrition education and poor integration into the continuing medical education curricula despite the fact that most residents understand the importance of nutrition and the need to consult experts in several situations.

A high number of doctors recommend to their patients, referral to a Registered Dietitian (92\%). In addition, $87.2 \%$ favor MNT before starting medical treatment or in parallel to it where applicable.

As this study shows, our current system of nutrition education must not only address the gaps in knowledge and effective clinical skills, but more importantly, must stress and work towards keeping the residents well versed in the subject of nutrition to serve the best interests of our patients. This may be one of the root causes explaining the poor adherence and effectiveness of nutritional therapies when it comes to treating the obese, diabetic patients, among others needing nutritional adjustments.

Finally, based on our alarming results, there is no doubt that actions to correct this major deficit are needed urgently. All sectors of the health care system should work to encourage multidisciplinary approaches to incorporate nutritional knowledge into the doctor's daily decision process. More in-depth studies are needed to show the best methods and the benefits of different nutritional interventions on the outcomes of different medical conditions. Those responsible for continuing medical education should make this integration a major target to improve preventive and therapeutic strategies in approaching medical education.

\section{References}

[1]. Hu SP, Wu MY, Liu JF. Nutrition knowledge, attitude and practice among primary care physicians in Taiwan. J Am Coll Nutr. 1997 Oct;16(5):439-42. PubMed PMID: 9322193.

[2]. Temple NJ. Survey of nutrition knowledge of Canadian physicians. J Am Coll Nutr. 1999 Feb;18(1):26-9. PubMed PMID: 10067655

[3]. Kushner RF. Barriers to providing nutrition counseling by physicians: a survey of primary care practitioners. Prev Med. 1995 Nov;24(6):546-52. PubMed PMID: 8610076.

[4]. Devries S, Dalen JE, Eisenberg DM, et al. Devries. A deficiency of nutrition education in medical training. Am J Med. 2014 Sep;127(9):804-6. doi: 10.1016/j.amjmed.2014.04.003. Epub 2014 Apr 19. PubMed PMID: 24754969.

[5]. Ireland K, Robbins J, Manders A, Lenders C. Assessment of student nutrition knowledge and self-efficacy at Boston University School of Medicine (118.1). The FASEB Journal. 2014 Apr 1;28(1 Supplement): 118.

6]. American Dietetic Association. Comparison of the American Dietetic Association (ADA) nutrition care process for nutrition education services and the ADA nutrition care process for medical nutrition therapy (MNT) services.

[7]. Dahan A, Altman H. Food-drug interaction: grapefruit juice augments drug bioavailability-mechanism, extent and relevance. Eur J Clin Nutr. 2004 Jan;58(1):1-9. PubMed PMID: 14679360.

[8]. Schaumburg H, Kaplan J, Windebank A, Vick N, Rasmus S, Pleasure $\mathrm{D}$, et al., Sensory neuropathy from pyridoxine abuse: a new megavitamin syndrome. N Engl J Med. 1983 Aug 25;309(8):445-8. PubMed PMID: 6308447.

[9]. McCabe BJ. Dietary tyramine and other pressor amines in MAOI regimens: a review. J Am Diet Assoc. 1986 Aug;86(8):1059-64. PubMed PMID: 3525654 .

[10]. Rowley WR, Bezold C, Arikan Y, Byrne E, Krohe S. Diabetes 2030: insights from yesterday, today, and future trends. Popul Health Manag. 2017 Feb;20(1):6-12. doi: 10.1089/pop.2015.0181. Epub 2016 Apr 28. PubMed PMID: 27124621.

[11]. American Diabetes Association. Standards of medical care in diabetes-2016. Diabetes Care. 2016;39(suppl 1):S1-S106.

[12]. Pastors JG, Warshaw H, Daly A, Franz M, Kulkarni K. The evidence for the effectiveness of medical nutrition therapy in diabetes management. Diabetes Care. 2002 Mar;25(3):608-13. PubMed PMID: 11874956.

[13]. Mayer SB, Jeffreys AS, Olsen MK, McDuffie JR, Feinglos MN, Yancy WS. Two diets with different haemoglobin A1c and antiglycaemic medication effects despite similar weight loss in type 2 diabetes. Diabetes Obes Metab. 2014 Jan;16(1):90-3. doi: 10.1111/dom.12191. Epub 2013 Aug 29. PubMed PMID: 23911112.

[14]. Piper C, Marossy A, Griffiths Z, Adegboye A. Evaluation of a type 2 diabetes prevention program using a commercial weight management provider for non-diabetic hyperglycemic patients referred by primary care in the UK. BMJ Open Diabetes Res Care. 2017 Oct 16;5(1):e000418.

[15]. American Dietetic Association Evidence Analysis Library.Medical nutrition therapy effectiveness for specific diseases or conditions. 2010.

[16]. Lacey K, Pritchett E. Nutrition Care Process and Model: ADA adopts road map to quality care and outcomes management. J Am Diet Assoc. 2003 Aug;103(8):1061-72. PubMed PMID: 12891159.

[17]. Elia M, De Silva A. Tight glucose control in intensive care units: an update with an emphasis on nutritional issues. Curr Opin Clin Nutr Metab Care. 2008 Jul;11(4):465-70. doi: 10.1097/MCO.0b013e3282fcea2a. PubMed PMID: 18542008.

[18]. Kuehneman T, Saulsbury D, Splett P, Chapman DB. Demonstrating the impact of nutrition intervention in a heart failure program. J Am Diet Assoc. 2002 Dec;102(12):1790-4. PubMed PMID: 12487542.

[19]. Centers for Disease Control and Prevention. Heart disease and stroke: The nation's leading killers. Atlanta, GA. 2007.

[20]. Arcand JA, Brazel S, Joliffe C, Choleva M, Berkoff F, Allard JP, et al., Education by a dietitian in patients with heart failure results in improved adherence with a sodium-restricted diet: a randomized trial. Am Heart J. 2005 Oct;150(4):716. PubMed PMID: 16209971.

[21]. Champagne CM. Dietary interventions on blood pressure: the Dietary Approaches to Stop Hypertension (DASH) trials. Nutr Rev. 2006 Feb;64(2 Pt 2):S53-6. PubMed PMID: 16532899.

[22]. Kaplan NM. Lifestyle modifications for prevention and treatment of hypertension. The Journal of Clinical Hypertension. 2004 Dec 1;6(12):716-9.

[23]. Delahanty LM, Sonnenberg LM, Hayden D, Nathan DM. Clinical and cost outcomes of medical nutrition therapy for hypercholesterolemia: a controlled trial. J Am Diet Assoc. 2001 Sep;101(9):1012-23. PubMed PMID: 11573752.

[24]. Sikand G, Kashyap ML, D Wong Na, Hsu JC. Dietitian intervention improves lipid values and saves medication costs in men with combined hyperlipidemia and a history of niacin noncompliance. J Am Diet Assoc. 2000 Feb;100(2):218-24. PubMed PMID: 10670395.

[25]. Mayes SL. Review of postmenopausal osteoporosis pharmacotherapy. Nutr Clin Pract. 2007 Jun;22(3):276-85. PubMed PMID: 17507728.

[26]. Cashman KD. Diet, nutrition, and bone health. J Nutr. 2007 Nov;137(11 Suppl):2507S-2512S. PubMed PMID: 17951494.

[27]. Niewinski MM. Advances in celiac disease and gluten-free diet. J Am Diet Assoc. 2008 Apr;108(4):661-72. doi: 10.1016/j.jada.2008.01.011. PubMed PMID: 18375224

[28]. Barker LA, Gout BS, Crowe TC. Hospital malnutrition: prevalence, identification and impact on patients and the healthcare system. Int J Environ Res Public Health. 2011 Feb;8(2):514-27. doi: 10.3390/ijerph8020514. Epub 
2011 Feb 16. PubMed PMID: 21556200.

[29]. Sharan. P, Sundar. AS. Eating disorders in women. Indian J Psychiatry. 2015 Jul; 57(Suppl 2): S286-S295. doi: 10.4103/0019-5545.161493.

[30]. Gout BS, Barker LA, Crowe TC. Malnutrition identification, diagnosis and dietetic referrals: are we doing a good enough job?. Nutrition \& Dietetics. 2009 Dec 1;66(4):206-11.

[31]. Lloyd-Jones DM, Hong Y, Labarthe D, Mozaffarian D, Appel LJ, et al. Defining and setting national goals for cardiovascular health promotion and disease reduction: the American Heart Association's strategic Impact Goal through 2020 and beyond. Circulation. 2010 Feb 2;121(4):586-613. doi: 10.1161/CIRCULATIONAHA.109.192703. Epub 2010 Jan 20. PubMed PMID: 20089546.

[32]. Mihalynuk TV, Scott CS, Coombs JB. Self-reported nutrition proficiency is positively correlated with the perceived quality of nutrition training of family physicians in Washington State. Am J Clin Nutr. 2003 May;77(5):1330-6. PubMed PMID: 12716690.

[33]. Vetter ML, Herring SJ, Sood M, Shah NR, Kalet AL. What do resident physicians know about nutrition? An evaluation of attitudes, self-perceived proficiency and knowledge. J Am Coll Nutr. 2008 Apr;27(2):287-98. PubMed PMID: 18689561.

[34]. Weimann A, Braga M, Carli F, Higashiguchi T, Hübner M, et al. ESPEN guideline: clinical nutrition in surgery. Clin Nutr. 2017 Jun;36(3):623650. doi: 10.1016/j.clnu.2017.02.013. Epub 2017 Mar 7. PubMed PMID: 28385477.

[35]. Ahmadi A, Ershad M, Givzadeh H, Mohammad-Beigi A. General physicians' knowledge about nutrition in Shiraz, Iran. Pakistan journal of biological sciences: PJBS. 2009 Jul;12(13):981-5.

[36]. Weinsier RL, Boker JR, Feldman EB, Read MS, Brooks CM. Nutrition knowledge of senior medical students: a collaborative study of southeastern medical schools. Am J Clin Nutr. 1986 Jun;43(6):959-68. PubMed PMID: 3717071 . 